\title{
Balancing Accuracy and Fluency in English Classroom Teaching to Improve Chinese Non- English Majors' Oral English Ability
}

\author{
Yuru Shen \\ School of Foreign Languages, Leshan Normal University, No. 778, Binhe Road, Leshan, Sichuan, 614004, China
}

\begin{abstract}
With the globalization of the world economy, especially with China's entry into the WTO, we will have to communicate more with people from all over the world in English, and as a result, an English learner's communicative competence, especially his or her oral communicative competence, is becoming increasingly important. College students, especially the non-English majors, account for a significant proportion of English learners in China. As far as they are concerned, how to help them express themselves both accurately and fluently in our English classroom teaching has been a matter of concern to us teachers of English for quite a long time. But despite the fact that a variety of means have been tried, for various reasons, a large number of non-English majors still have much difficulty expressing themselves effectively. So this paper is intended to solve the problem. It first reveals the current overall level of the Chinese nonEnglish majors' spoken English, then probes into the factors responsible for their poor oral English ability, and finally proposes a practical, applicable and effective solution to the problem: balancing accuracy and fluency in English classroom teaching.
\end{abstract}

Index Terms - oral English ability, factors, accuracy, fluency, balance, improve

\section{INTRODUCTION}

With the globalization of the world economy, especially with China's entry into the WTO, we will have to communicate more with people from all over the world in English, a widely recognized universal language, and as a result, an English learner's communicative competence, especially his or her oral communicative competence, is becoming increasingly important. College students, especially the non-English majors, account for a significant proportion of English learners in China. As far as they are concerned, how to help them express themselves both accurately and fluently in our English classroom teaching has been a matter of concern to us teachers of English for quite a long time. But despite the fact that a variety of means have been tried, a survey on "Hierarchical Teaching" made in Leshan Normal University in 2011 revealed that a large number of non-English majors still had much difficulty expressing themselves effectively. Then how to improve their oral English ability? This paper is intended to find a satisfactory answer to the question. To achieve the purpose, it will first reveal the current overall level of the Chinese non-English majors' spoken English and then probe into the factors responsible for their poor oral English ability.

\section{The Current Oral English LeVel of Chinese Non-English Majors}

In June 2011, a survey on "Hierarchical Teaching" was conducted by the writer and her colleagues in Leshan Normal University. The participants in this survey were 1,218 Level-A and 540 Level-B non-English majors in their second year. They had studied English more or less entirely in an instructed setting. They were between 18 and 20 years old. At the time of data collection, most of them had been studying English as a foreign language in Chinese schools for 8 years, first in elementary school and middle school and then in college. None of them had ever been to an English-speaking country, and they had had few opportunities to use English for communicative purposes outside the classroom. As non-English majors, they had 4 hours of English per week-3 hours for intensive reading and 1 hour for listening (A few teachers use half an hour for speaking every two or three weeks or occasionally). They were not told the precise purpose of the survey and were assured that the information collected would not impact their course grades.

All the participants were asked to complete a questionnaire in Chinese. The questionnaire consisted of multiple choice questions on their English study habits, English learning strategies, learning methods and so on and three open-ended questions on their opinions mainly about "Hierarchical Teaching." For instance, there are such questions as "Which language skill do you want to improve most---Listening? Speaking? Reading? Writing?", "What do you think is the biggest obstacle to improving your English ability---Limited vocabulary? Insufficient English knowledge? 
Insufficient background knowledge? Lack of interest? Not realizing the importance of improving oral English ability?" and "What do you think is the major problem in English classroom teaching---Teachers' overuse of Chinese? Teachers' overuse of criticism? Teachers' overuse of the traditional teaching mode? Teachers' monotonous use of classroom teaching language?"

By classifying and analyzing the data collected, we found that $58.2 \%$ of the participants agreed that of the four language skills, speaking was the skill that they wanted to improve most and therefore they suggested that the teacher organize more speaking activities in class, while $32.18 \%$ thought they should do more listening exercises before required to speak; $49.44 \%$ named speaking as the skill they got the least practice at the individual level; $44.07 \%$ admitted that they couldn't make themselves understood most of the time, not to speak of expressing themselves fluently. As to the factors resulting in their poor oral English ability, $48 \%$ of the participants mentioned their limited vocabulary, 30\% referred to their neglecting the importance of improving their spoken English in college and $19.2 \%$ thought of their lack of interest in English study as the main factor. As for the major problem in English classroom teaching, 64\% mentioned that their teachers spoke too much Chinese in class.

Different participants had different answers to the questions raised in the questionnaire and we cannot list them one by one, but the survey indicates that most Chinese non-English majors are weakest in the productive skills---speaking and writing, with speaking featuring significantly as the skill which needs most attention, and that the factors responsible for this result are various.

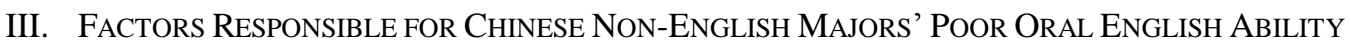

Without doubt, many factors, such as the teachers' negative impact and students' lack of interest in English, are responsible for the poor oral English ability of many Chinese non-English majors, but, based on our survey and observation, we find that the following are the major ones.

\section{A. Teachers' Negative Impact}

We all know that oral communication through participation and interaction is the basis on which spoken language is built. But the survey mentioned above suggests that some of the teachers' practices in class limit or affect Chinese non-English majors' oral communication in class and as a result, lead to their poor oral English ability.

1. Teachers' Overuse of Chinese

My observation also confirmed that a large number of teachers of English spoke too much Chinese in class.

Two years ago, to get to know how teachers who taught non-English majors English in our college conducted their teaching, I observed the English classroom teaching of fifteen teachers for a month on end. The result was surprising: About $80 \%$ of the teachers observed used both English and Chinese to give instructions, explain the learning materials and make informal interaction with students. That is, most of the time they spoke English first and then translated what was said into Chinese immediately. About $13 \%$ lectured all the way through a class in Chinese except reading the English texts or exercises. Only one teacher spoke English most of the time, only occasionally translating the difficult or important points into Chinese to help students have a better understanding. 90\% used "Grammar Translation" method, with which they analyzed the structures of most sentences in a passage, and then translated them into Chinese, or asked students to do translation exercises now and then. In the opinion of these teachers, mastering grammar (through translation) is the main objective of English study, and communication, if it occurs, is the lucky byproduct. Teachers' speaking too much Chinese in class makes students mistakenly believe that studying English is just studying how to do translation from English to Chinese or vice versa and as a consequence, affects their effective expression of themselves.

2. Teachers' Underuse of Praise

As to the importance of praise, Janet Graham, an English composer, music educator and music therapist, said in her essay "Profits of Praise" that "Praise is like sunlight to the human spirit; we cannot flower and grow without it. . . . For children an ounce of praise is worth a pound of scolding" (qtd. in Zai, 1998). Unfortunately, although many teachers are fully aware of the importance of praise to students in elementary or middle schools and therefore they often give students pats on the back, even for a little progress, yet few have realized the great effects praise may also have on college students, especially on the underachievers. Quite a few teachers in college have the misconception that as grown-ups, college students should know clearly what they should and can do and that they shouldn't do something just because they can get plenty of praise or encouragement if they do it. So, instead of praising students now and then, many teachers always find fault with what their students say and say something discouraging. They usually attach too much importance to the grammatical correctness of sentences. It is true that grammar is an absolute necessity in language teaching and learning, but they haven't realized that if a student is frequently scolded because of some careless grammar mistakes in his or her oral presentation, he or she will become timid and afraid of making mistakes, and as a result, he or she would rather "play safe" by keeping silent instead of making bold attempts to speak out. Since no one likes to be criticized, why don't we make more efforts to relay more pleasing and flattering comments? Why are we reluctant to give our students the warm sunshine of praise? 


\section{B. Interference of Chinese}

In China, English is taught in an EFL context. Teachers of English and students share the same mother-tongue, Chinese. Having been surrounded with Chinese and influenced by the Chinese thought pattern since they were born--beating about the bush, many students construct English sentences as they do in Chinese unconsciously. But some teachers consciously or unconsciously neglect and fail to correct their mistakes in time, by and by, the students' bad habit of constructing English sentences in a Chinese way take hold. Whenever they are required to translate Chinese into English, they would make word-for-word translation unconsciously. As a result, what they speak is Chinglish, inappropriate in form and meaning.

\section{Boring and Mechanical Speaking Activities}

Because of paying too much attention to the study of language knowledge, many teachers often create EFL contexts where students are given much explicit explanation of forms and limited oral production practice, like gap filling, sentence writing, sentence translation, paragraph translation and so on, instead of providing students with opportunities for "practice in real-operating conditions or optimal operating conditions" (Johnson, 1996; Van denBranden, 1997, 2007; qtd. in Patanasorn, 2010). Even if some oral activities are organized, they are such boring and mechanical ones as "reading model dialogues," "reading aloud comprehension passages," "giving answers to written language exercises," "reading aloud vocabulary lists," "reading after the tape," and "watching a video or clip of a film and then repeating some "excellent' lines." These activities just help students "to vocalize the sounds of English and to be familiar with the structures of English leading to linguistic competence" (Lan, 1994), which, important though it is from the accuracy aspect of speaking, will remain only as building blocks. These building blocks will not be put to use for which they are made, which is to develop the speaking skill, because the oral activities do not require students to "formulate utterances based on process of language for production in real time under reciprocity conditions" (Lan, 1994). Just because students do not receive authentic oral production practice frequently in their language classes, their oral English ability is hard to get improved.

\section{Deficient Testing System}

Nowadays, almost all the English tests at different levels in China, from elementary school to high school to college, emphasize accuracy. For example, the English achievement test for the non-English majors in colleges and universities usually consists of two parts: subjective items like compound dictation, translating and writing, which accounts for 30-35\%, and objective items like in-depth reading, fast reading, listening comprehension and cloze, which accounts for $65-70 \%$. In a vast majority of colleges and universities, there is no oral test at all. Let's take CET-4 (College English Test Band 4) for another example. Almost all the students in almost all the colleges and universities are required to pass the written examination to acquire the diploma, but only a few (those who get a score of 85 points or more) can have the opportunity to take part in the College English Level Four Spoken English Test. What's worse, test makers often offer four reasonably sounding words or phrases or sentences for students to choose from and the students are compelled to spend three-fourths of their time looking at wrong or inappropriate usages. Although educators and teachers know clearly that exposure to too many wrong answers in multiple choice questions does great harm to students' second language acquisition in terms of "use" rather than "usage," they still prepare such examination questions. To help students pass such examinations with ease, teachers have to take much class time to differentiate one word from another and one phrase from another. Similarly, students have to devote most of their time and energy to memorizing the subtle differences between words and between phrases in the hope that they can pass the CET-4 or 6 exam or other English examinations without any difficulty. There is hardly any peer interaction or teacher-student interaction in or after class. So the deficient testing system is also a very important factor responsible for students' poor language proficiency.

Besides the teachers' negative impact, the interference of the mother tongue, the boring and mechanical speaking activities and the deficient testing system discussed above, some other factors, like the speaker's introverted personality, lack of self-confidence, poor physical conditions, unfamiliarity with the situation, inadequate preparation and so on, also prevent students from expressing themselves both accurately and fluently. To solve the problem, my colleagues have tried various means, but in vain. As far as I'm concerned, the key to solving the problem is to maintain a balance between accuracy and fluency in classroom teaching, because "because of the time-constraint and reciprocity conditions inherent in listener-speaker situations" and "the need to handle unpredictability of listener response," "spoken language proficiency involves being able to produce fluently and accurately, autonomous utterances which are appropriate to the context of the speech situation" (Lan, 1994).

\section{ACCURACY AND FLUENCY}

As far as accuracy and fluency are concerned, different scholars have given different definitions. For example, Ellis (2009) holds that "fluency" means "the capacity to use language in real time, to emphasize meanings, possibly drawing on more lexicalized systems," and "accuracy" means "the ability to avoid error in performance, possibly 
reflecting higher levels of control in the language as well as a conservative orientation, that is, avoidance of challenging structures that might provoke error." Crystal (1977), Bryne (1986), and Nation (1991) define "fluency" as "the ability to get across communicative intent without too much hesitation and too many pauses to cause barriers or a breakdown in communication" (qtd. in Lan, 1994). Bryne (1988) defines "accuracy" as "the use of correct forms where utterances do not contain errors affecting the phonological, syntactic, semantic or discourse features of a language" (qtd. in Lan, 1994).

But in this paper, "accuracy" refers to the ability to produce grammatically correct sentences while "fluency" refers to the quality or condition of being able to speak or write a language or perform an action smoothly, accurately and easily, which includes the ability to produce written and/or spoken language with ease, the ability to speak with a good but not necessarily perfect command of intonation, vocabulary, and grammar, the ability to communicate ideas effectively, and the ability to produce continuous speech without causing comprehension difficulties or a breakdown of communication. In other words, accuracy emphasizes precision or exactness and is often emphasized in formal instruction, language acquisition, grammar competence and grammar-translation method, while fluency describes a level of proficiency in communication and is frequently stressed in procedural skill, expression proficiency, lexical phrases, social interaction, necessary topics and discourse. Accuracy is the basis of fluency while fluency is a further improvement of a person's linguistic competence and a better revelation of his/her communicative competence. They two are so closely related that they are inseparable.

Nevertheless, most teachers of English in China prefer either accuracy-oriented activities or fluency-oriented ones. Then what can we do to balance the two in our classroom teaching?

\section{Methods of Balancing ACCuRACy AND Fluency In English Classroom Teaching}

To keep a balance between accuracy and fluency in our English classroom teaching, we can employ the following methods.

\section{A. Combining Communicative Approach with Grammar-translation Method}

Nowadays, with greater importance being attached to English learners' communicative competence, which involves principles of appropriateness and a readiness on the part of the learner to use relevant strategies in coping with certain language situations, communicative approach has been advocated and is being practiced in college English teaching. But with the passage of time, we have found that no single teaching method can deal with everything that concerns the form, the use, and the content of the target language and that appropriate grammar analysis and limited utilization of translation from or to the target language (English) are still an indispensable part of teaching. Vocabulary work and pattern drills are still good ways of familiarizing students with sentence structures and thus can help them acquire linguistic competence, which, involving the spontaneous, flexible, and correct manipulation of the language system, is the basis on which English language skills get improved. So we had better combine communicative approach with grammar-translation method in our classroom teaching. In this way students can not only acquire a solid knowledge of the English language but also better their English language skills.

To combine the two methods well, we need to make the language situations and language material as realistic as possible or make English teaching partly communicatively oriented so as to help students acquaint themselves with appropriate language usage instead of just teaching grammar and drilling grammar patterns as we used to. That is to say, while practicing linguistic competence, classroom activities such as role playing, simulations, and real-life interactions should also be organized to provide as much practice as possible for students to develop their communicative competence.

\section{B. Encouraging Guided Peer-interaction and Student-teacher Interaction}

To what extent should we make efforts to encourage the non-English majors to make spontaneous and unsupervised peer-interaction in English? The answer is "we must be cautious." Although students can acquire the second language through classroom communication or interaction, the unsupervised or unguided peer-interaction in EFL contexts will undoubtedly expose them to a large number of wrong forms. If they practice their spoken English in this way for a long time, they may speak some classroom pidgin, a language made up of two or more languages. Fluency will be emphasized at the expense of accuracy. To avoid it, we had better encourage guided peer-interaction by offering students some hints before and during the whole interactive activity. We can remove the linguistic "props" of already formulated structures as soon as possible so as to provide a balance between activities focused on linguistic forms and those focused on language use to help learners achieve autonomy. Suppose, before we require students to answer the reading comprehension questions orally about the narrative essay "Toby Trivisono's American Dream" written by Frederick C. Crawford, an American industrialist and philanthropist (qtd. in Ji, 2010), we may provide the interesting details of the passage in the form of a table like the following: 


\begin{tabular}{|l|l|}
\hline Who is the main character? & \\
\hline Where was he from? & \\
\hline When did he go to America? & \\
\hline Why did he go to America? & \\
\hline What was his dream? & \\
\hline How did he realize his American Dream? & \\
\hline
\end{tabular}

Because the points abstracted indicate the essence of the passage, by answering the questions, students can not only practice their spoken English but also improve their reading comprehension ability. In fact, we can organize other speaking activities in the same way. For instance, if we want a student to make an oral report on his or her trip to some place, we can ask him or her to answer the six journal questions (who, where, when, why, what, and how). With teachers' guidance, students will find it much easier to make oral production. With teachers' correct and appropriate guidance and if necessary, with their indirect correction, students may be more likely to notice the differences between their output and correct forms. The more guided peer-interaction there is, the more comprehensible input there will be. As time goes by, students will gradually move up the scale of communicativeness towards autonomy.

Besides encouraging guided peer-interaction, we had better encourage more student-teacher interaction in and after class. Teachers, usually with rich English knowledge and strong English skills, can act as models as well as guides to students. With teachers' imperceptible correction of mistakes and with their occasional encouragement, students will gain confidence and be bold enough to speak more and gradually they can express themselves effectively.

\section{Teachers' Transferring Their Roles}

With more and more attention being focused on improving students' communicative competence, the roles teachers have to play must be redefined. The best teachers are usually the ones who impart an attitude or an orientation related to the acquisition of mental abilities, or who are associated with the particular values that one finds personally motivating and inspirational. Specifically speaking, we teachers should take on the following roles in modern English classroom teaching.

First, instead of being the dominating authority in the classroom, we must become learning facilitators to "facilitate the communicative process between all participants in the classroom and between these participants and the various activities and texts" (Breen \& Candlin, 1980), giving guidance and advice when necessary. We should also "act as interdependent participants within the learning-teaching group" (Breen \& Candlin, 1980), which means that we need to perceive students as having important contributions to make, and then we must continually seek potential and exploit and actively share the responsibility for learning and teaching with them. We must realize that any unnecessary intervention from us may prevent them from becoming genuinely involved in the activities and thus hinder the development of their communicative skills. However, this does not necessarily mean that we should be passive observers. Instead, we should develop students' potential through external direction and help them develop their distinctive qualities.

Second, just as we want students to be life-long learners, we teachers must exhibit a passion for learning, a desire and an aptitude to continue discovering new knowledge and exemplify by constantly refreshing our knowledge and skills to keep abreast with the latest developments in our area of specialization.

Third, to keep pace with the times, we teachers also need to be creative and innovative in integrating our teaching with thinking and learning processes. We must give students more opportunities for expression and provide an environment where creativity can flourish. And we must encourage students to question and to express their thoughts freely so that they will have inquisitive minds.

Besides, because the dynamics of society and industry are changing very fast and whatever knowledge and skills one acquires today may not be relevant tomorrow, we teachers need to remain sensitive and receptive to changes and to be able to anticipate further changes that may come their way. And at the same time we must inculcate in our students a mindset for adapting and receiving changes to prepare them for the changing need of society.

In a word, in addition to imparting knowledge, we teachers need to be in the best positions to determine the most effective teaching methods to bring out the best in each student. For this purpose, on the one hand, we need to recognize learning as an interpersonal undertaking over which no single person can have full control, and realize that there will be differences between ongoing learning processes. We have to accept the fact that "different learners learn different things in different ways at different times" and that some learners may "enter periods when it seems that little or no progress is being made" and that "sometimes learning is typified by silent reflection." On the other hand, we should continually develop new skills and embrace new ideas to bring a fresh perspective to every lesson and to inspire in our students a love for learning and passion for their subject; we should motivate students to always make full use of their time, talents and abilities; we should develop students as individuals according to their talents and abilities. In other words, to help students fit in with the needs of the society, we should work as organizers of resources and as resources; as guides and managers of the classroom procedures and activities and as researchers and learners, "with much to contribute in terms of appropriate knowledge, abilities, and actual and observed experience in the nature of learning and organizational capabilities" (Breen and Candlin, 1980). 


\section{Teachers' Equipping Themselves with Knowledge and Appropriate Teaching Methods}

Liu Runqing, professor of English at Beijing Foreign Studies University, once said, a teacher must take into account two things in his actual teaching---"What to teach?" and "How to teach?"

"What to teach?" involves pronunciation, vocabulary, grammar, semantics, discourse, pragmatics and the ability and skill in listening, speaking, reading, writing and translation, while "How to teach?" or "How do you teach the language?" has something to do with the teaching method a teacher may use in his teaching. "What to teach?" and "How to teach?" require us teachers to be equipped with all kinds of knowledge. To put it another way, not only should we know something about linguistics, psychology, sociology, anthropology, education and so on, and be able to demonstrate the target language with enough accuracy, but we are also expected to know a variety of teaching methodologies, correct ways to research, and some basic principles of testing. We must realize that it is obligatory for us teachers to adopt different methods when dealing with different teaching materials and when faced with students with different levels of English proficiency. To achieve the purpose, we must enrich our knowledge of English and improve our English skills by various means such as listening to programs in English, watching English programs on TV and surfing the English versions of various news items on the Internet frequently. In a word, to improve students' oral proficiency, we teachers should try every possible means to make ourselves walking encyclopedias so that we can teach any student anything with skill and ease.

\section{E. Attaching Equal Importance to Both Accuracy and Fluency Exercises}

As is mentioned above, accuracy and fluency are so closely related that they are inseparable. Skehan (1998) proposed that "because learners have a limited capacity of attention, there could be trade-off effects between accuracy and fluency. That is, when attention is paid to accuracy, fluency is likely to suffer and vice versa" (qtd. in Patanasorn, 2010). So attaching equal importance to both accuracy and fluency exercises is a must.

Accuracy exercises encourage a thoughtful use of language and the information is intended to help students understand how English works, while fluency exercises invite them to take the parts of different characters when roleplaying and to continue a dialogue in their own way, that is, the fluency exercises encourage free expression. Doing accuracy exercises does not mean 100\% error-free, but a high degree of accuracy is required, and as a result, students are encouraged to make as few errors as possible and to manipulate the language as spontaneously and flexibly as possible. Generally speaking, soon after the students have mastered the language forms, they ought to be given intensive fluency practice, which is directed at inviting them to express themselves freely without being at all concerned about $100 \%$ accuracy. At this stage, we should not only tolerate students' errors and encourage them by emphasizing that error-making is a natural and common practice in the learning of a foreign language, but also assess their performances at the end of each fluency practice so that they can realize their own weaknesses and become more and more conscious of their errors. In this way, accuracy and fluency, which are interdependent, can be practiced almost simultaneously.

But when assigning accuracy and fluency exercises, we had better keep in mind the following:

For one thing, we had better assign exercises that need the knowledge with which students are familiar, because it is found that the personal task which is based on information well known to learners allows them to be more fluent in their performance.

For another, we had better give students more planning time. "With regards to planning, it has been suggested that providing learners with more planning time prior to conducting the task helps learners produce more fluent and complex language" (Patanasorn, 2010). Generally, the more planning time they are given, the more familiar they will be with the inherent structure of discourse and as a result, the more accurate and fluent they will be in their performance, because "familiarity with content and opportunity to plan help lessen the load of information processing which allows learners more attentional resources to focus on formal aspects of language as well as help them to become more fluent in their performance" (Patanasorn, 2010).

In addition to the methods discussed above, we can also achieve the purpose of improving Chinese non-English majors' spoken language proficiency by praising the efforts or even a little progress they make in their English study or by changing the question types in the examination. For example, we can increase the value of the existing subjective items and if possible, we can offer a spoken English test in the final examination. In that case, both teachers and students will be compelled to pay equal attention to accuracy and fluency in their teaching and learning.

\section{CONCLUSION}

In conclusion, with people's attention being focused more and more on the oral proficiency of English learners, teachers have realized the urgency of shifting their emphasis from form to use and communicative language principles are subscribed to. But the reality is that linguistic competence continues to be emphasized while there is no corresponding change in the classroom teaching modes and teaching methods. Hence, what we should do now is conscientiously try to shift our attention from emphasizing the accuracy of students' oral presentation to developing 
their ability to express themselves both accurately and fluently in English, for which we can employ various means such as combining grammar-translation method and communicative approach, transferring teachers' roles, and attaching equal importance to both accuracy and fluency exercises.

\section{REFERENCES}

[1] Alleen Pace Nilsen and Don L. F. Nilsen. (Jan. 2003). Vocabulary Development: Teaching vs. Testing. English Journal. 92 (3), 31-37.

[2] Breen, Michael P. and Candlin Christopher N. (1980). The Essentials of a Communicative Curriculum in Language Teaching. Applied Linguistics, 1(2): 89-112.

[3] Brown, G.K., Malmkjaer. A. Pollitt and J. Williams. (1999). Language and Understanding. Shanghai: Shanghai Foreign Language Education Press.

[4] Brumfit, C.J. and K. Johnson. (2000). The Communicative Approach to Language Teaching. Shanghai: Shanghai Foreign Language Education Press.

[5] Ellis, Rod. (2009). The Differential Effects of Three Types of Task Planning on the Fluency, Complexity, and Accuracy in L2 Oral Production. Applied Linguistics, 30/4: 474-509. doi:10.1093/ applin/amp042.

[6] Ji Peiying, Wu Xiaozhen, \& Chen Jin. (2010). New College English: Integrated Course 1 (2nd ed.). Shanghai: Shanghai Foreign Language Education Press.

[7] Lan, Lim Soh. (Oct. 1994). Fluency and Accuracy in Spoken English---Implications for Classroom Practice in a Bilingual Context. The English Teacher, Vol. XXIII. Retrieved August 28, 2012, from http:// www.melta.org.my/ ET/ 1994/main4.html.

[8] Liu Runqing. (1988). On English Language Teaching. Beijing: Beijing Foreign Language Teaching and Research Press.

[9] Patanasorn, Chomraj. (Apr. 2012). Effects of Procedural, Content, and Task Repetition on Accuracy and Fluency in an EFL Context. Unpublished doctoral dissertation, Northern Arizona University, Arizona.

[10] Zai, Xiangjun. (1998). College English: Intensive Reading (Revised edition). Shanghai: Shanghai Foreign Language Education Press.

Yuru Shen was born in Meishan, China in 1966. She received her master's degree in language and literature from East China Normal University, China in 1998.

She is currently a professor in the School of Foreign Languages, Leshan Normal University, Leshan, China. Her research interests include English pedagogical theory and practice and English writing.

Prof. Shen is a member of the CELEA (China English Language Education Association) Writing Professional Committee. 